\title{
Enterprise Social Network Success: Evidences from a Multinational Corporation
}

\author{
Bruno Faria*1 (0000-0002-8376-5791) and Rui Dinis $\operatorname{Sousa}^{2}(0000-0001-7607-555 X)$ \\ ${ }^{1}$ University of Minho, Guimarães 4804-533, Portugal \\ a69174 ealunos.uminho.pt \\ ${ }^{2}$ Information Systems Department, ALGORITMI Research Centre, University of Minho, \\ Guimarães 4804-533, Portugal \\ rdsedsi. uminho.pt
}

\begin{abstract}
In a globalized world, where companies operate across different locations and work becomes increasingly complex, collaboration in a diversity of ways is required among employees to perform tasks more effectively. Following a case study methodology that involved six interviews across three different country locations, this research addresses the phenomenon of Enterprise Social Networks (ESN) in a multinational corporation with a focus on the assessment of ESN success.

The findings show that the company, while trying to assess the success of Yammer, the freemium social networking service at use, has mainly relied on analytics tools to measure usage through indicators such as the total number of users. However, the extent to which ESN is used does not provide a complete picture of ESN success. Business value from that ESN usage is another dimension to be considered to assess success. Therefore, the study of specific ESN usage scenarios that are perceived to have a trackable impact on business results can be used to assess ESN business value on top of ESN usage to fully understand ESN success.
\end{abstract}

Keywords: Enterprise Social Networks, Benefits, Success Criteria, Success Assessment.

\section{Introduction}

As the name suggests, Enterprise Social Networks are social networks that were tailored to meet specific requirements of the organizational context, to engage and connect employees, to boost collaboration, communication, information exchange, and to create a community feeling among users [1,2]. Different authors use different denominations when they address ESN topics, e.g., Social Networking Technologies [3] or Enterprise Social Networking Systems [4]. An evidence of a young research field in development [5]. Usually, these platforms support several social media functionalities such as status updates, microblogging, groups and communities, instant messaging, or content management. ESN also provide personal profiles, the possibility to like and comment content and to follow or unfollow different users [6]. By increasing interaction between employees and encouraging collaboration and communication, knowledge management infrastructures are being incorporated with social features to 
capture tacit, social and individual knowledge [6,8]. These technologies became very important in large and distributed companies to support knowledge sharing among individuals, teams and units spread by different geographical locations and time zones [8]. Employees choose to meet new people instead of just reaching out to people they already know, sharing work and non-work-related content, and using the platform to spread messages to larger audiences [9].However, there is a small understanding of how ESN can be used in organizational simple work practices [2]. Organizations have difficulties to assess the potentialities of Enterprise Social Software (ESS) in general, in which ESN are included. Nevertheless, the lack of knowledge about these technologies makes organizations to implement them without clearly defining the strategy and the expected business outcomes [10]. Therefore, this work, following a case study methodology, intends to provide some insights on ESN, pursuing an answer to the following research question "How to assess the success of Enterprise Social Networks?", in the context of a multinational corporation.

\section{Enterprise Social Networks Success}

Delone and McLean IS success model [11] is one of the first research initiatives trying to provide a holistic overview on the topic of Information Systems success measurement. An extensive literature review has highlighted a set of metrics used over the years to assess IS success in categories as system quality, information quality, use, user satisfaction, individual impact, and organizational impact. However, Richter et al [12] argue that existing theories and models fail by being too theoretical as they don't provide examples on how success can be measured in a practical way.

Large multinational organizations are increasingly dependent on successful knowledge sharing among individuals, teams, and units because of their high degree of geographical dispersion throughout locations and time zones, what has led to the adoption of ESN [8]. Even though there are several models explaining the adoption of technology, "acceptance is not equivalent to success, but rather a necessary precondition to success" [12]. Success seems to be a much broader concept then just having users using the tool.

As more ESN start to be used in organizations, it becomes important to understand how the success of these platforms can be measured. If on one side decision makers have to justify their Information Technology (IT) investments and the owner of the system wants to improve the usage of the platform, on the other side, the added value of the ESN use must also be understood by users [12]. Herzog et al. [13] support the same idea as they refer many IT executives are pressured to clearly show the benefits of using such technologies recurring to understandable methods and indicators. However, the impact of using those technologies is not easy to prove.

Steinhueser et al [14] propose a set of indicators and barriers to measure ESS expenditures, assets, use and organizational performance impacts. A McKinsey study has presented a matrix highlighting the increase in the value added for different types of Enterprise 2.0 technologies for different levels of penetration of the technologies in the organization. The results come from a survey conducted between 2007 and 2015 in 1500 companies. However, the study doesn't provide any guidelines about how these returns can be assessed for specific technologies in specific organizations [15]. 
A set of measures for the ESS success and group them in two categories: usage and business value [13]. To tackle the inexistence of an "integrated and easy to apply approach" to measure ESN success, a very similar approach that identifies measures for seven specific ESN usage scenarios [12]. The resulting Success Measurement Framework is also structured in two dimensions: usage and business value. The authors distinguish between the measurement of the usage of the platform, that usually can be assessed using analytics platforms, and the measurement of the organisational impact caused by ESN usage. Business value can be measured in the form of business cases analysis or return on investment.

\section{$3 \quad$ Research Methodology}

\subsection{Organizational and Technological Context}

This study was conducted in a company with around 24000 employees across more than 120 countries. The company has introduced Yammer (http://yammer.com/), an Enterprise Social Network provided by Microsoft, in 2014. After a series of initiatives to introduce the platform and engage users, the network keeps growing and has already 22000 users (May 2017). The company has also access to Tryane Yammer Analytics (https://tryane.com/en/yammer_analytics.html), a web-based analytics tool that provides insights into Yammer activity at global and group level.

\subsection{Interviews}

As the final goal of the study was to understand how the success was measured, the interviews were developed around this topic in a semi-structured way. Four interviews were conducted in person and two interviews were conducted using Skype for Business. All the interviews were recorded and, then, transcribed using oTranscribe (http://otranscribe.com/), a freemium web application suited for the task, and, then, analyzed using QDA Miner Lite (http://provalisresearch.com/products/qualitativedata-analysis-software/freeware/), a freemium qualitative text analysis software. Some emails were also exchanged to clarify some aspects from the interviews.

\subsection{Interviewees}

Six semi-structured interviews were conducted to five IT employees and to one product manager from Mexico. These five IT employees are the ones that have been responsible for tracking ESN success in the company along the years. INT-1 and INT-2, were the project leads of the initiatives undertaken to implement and launch Yammer. One interviewee, INT-3, was part of both teams during that process. INT-4 is the current owner of the tool and INT-5 is the head of the IT sub-department responsible for the collaboration technologies. INT-6, Head of Product Management in Mexico, is the only non-IT interviewee. He developed a competition on Yammer that is the current best example of how Yammer has impacted business results in this corporation. 


\section{$4 \quad$ Assessing ESN Success}

\subsection{Analytics Tools}

Analytics tools are a good resource to evaluate the health of a network. According to INT-1, the level of engagement - percentage of users accessing the platform -, the number of new users and the number of active groups, on daily and weekly basis, were some of the indicators used to measure the adoption of the platform, and, therefore, the health of the network. "If you have fifty or over engagement, you are doing really well with your users. We looked anywhere that 30-50\% range of engagement as being very good. So, we definitely did analytics and looked at them weekly and provided the status report for our management." (INT-1). For INT-2, on a high level, the main success criteria was to enable the exchange of knowledge and, then, to achieve a sustainable usage: "we achieved it, we are not great, but we are in a good track, this is what we achieved, so more than $40 \%$ of our usage rate". INT-5 also believes the main target was to "Get users on and get them engaged", because the biggest success criteria is to keep the engagement and the excitement with the platform high. "Social networking is only working with participation (...) from a huge community" (INT-5).

Based on the assumption users "wouldn't be active if it [Yammer] was not something that helps them" (INT-3), the increasing of engagement means new users found the network beneficial for them. However, it is a challenge to retrieve meaning out of the analytics and clearly understand what are the specific reasons triggering increasing usage. "We can increase now $1 \%$ [of engagement], but what does that $1 \%$ mean? And then, maybe, we don't know why that increase is happening. [If] We cannot measure that, how can we replicate it?" (INT-4).

Because social networks live from the excitement and the contributions of their user bases, understanding the reasons behind usage is important because they could be advertised and make other users to join and to start contributing for the network. " $1 \%$ increase is because, suddenly, Japan started using it a lot. Maybe, in the global scale, it's not that much. But if we replicate that in other regions, then, that $1 \%$ means $10 \%$, and that would be significant." (INT-4).

Analytics tools like Tryane Yammer Analytics provide a set of indicators as the number of comments, likes, most active discussions, more active groups, or more discussed topics. That information is helpful by providing insights into the level of collaboration, communication and information exchange inside the tool.

\subsection{Limitations of Analytics Tools}

There is a set of inherent benefits to the usage of social networks that can't be clearly measured recurring to analytics tools. By using Yammer, "people feel integrated, but what exactly does that mean? A remote user, in a remote location, that does not talk too much with his team? Or does that apply even on the region level or in a global team?"(INT-4). It seems important to understand these aspects in a deeper level. "I think that if you don't measure something, then there is no way to improve. And that's the challenge usually we have. That's the challenge also with those benefits.". 
On the other side, if we want to relate Yammer to productivity gains, the task can get even harder. INT-2 expresses the difficulty in measuring the productivity gains because there are different aspects that can influence productivity. INT-3 follows the same idea: "the effect of collaboration cannot be directly putted to euros science". INT4 adds: "The benefits are there, but if we want to put a number, a money value, to that, that might be a little bit more tricky." To execute this kind of analysis, the solution seems to resort on high level studies that have focused on the topic. McKinsey's study "Taking the measure of the networked enterprise" [15] relates the percentage of penetration of different Enterprise 2.0 technologies to companies results. "I came back to the situation of 20/30 million yearly that should bring for [the company]. (...) We had, in that year, also a huge productivity gain, when we started to do it properly. But I would not be so bold to say all of that is related to that [Yammer], but some portion of it, definitely, is based on Yammer. It would be wrong to say there is a real correlation.".

\subsection{Resorting to Specific Usage Scenarios}

One case from the Mexican Sales Organization is a good example on how benefits from using Yammer can be assessed. Globally, one of the organizational targets for the sales agents is the performance of product demonstrations, however, in the Mexican organization, there wasn't a strong culture of product demos. On average, a sales agent performed 0,3 demonstrations per day. Even though, in a survey answered by sales agents and sales managers, $40.5 \%$ said that more than half of the demonstrations resulted in one products sale.

Because product demonstrations seem to be related to sales, - "If you don't do demos, you lose money." (INT-6) -, there was the idea to create a competition among sales agents to promote product demonstrations in an exciting way. The competition was developed from February 2016 till December 2016 and Yammer was the driving platform used. In a brief way, each sales agent should upload demo photos or videos in the Yammer group and, then, he or she would be awarded points depending on the product being demonstrated. Strategic products were worth more points. The number of likes received in a specific demo would also be converted in points. Sales agents had the possibility to challenge others to perform demos. If the challenge wasn't accepted, points would be deducted from the challenged sales agent's overall score.

In the end of the competition, prizes were awarded to the agents in the top of the ranking. The results showed an increase on the rate "number of demos per sales agent, per day" from 0,3 to 1,40 . The top 10 sales agents also achieved a sales result $3 \%$ above the plan. Furthermore, the competition was important for the sales guys that worked in remote areas to feel integrated in the team and to make a change on sales agents' mind: making product demonstration wasn't an imposition, but something natural to do.

The Yammer group used during the competition was week after week among the five most active groups in the network, what can be correlated with the following statement: "I do believe by reviewing the Yammer analytics for groups and individuals that you should be able to directly correlate increased collaboration with relationships to new innovations, improved processes, decreased implementation times, successful product launches, increased sales and even happier employees" (INT-1). 
Initiatives like this one provide a good example on how the success of ESN can be assessed in a more understandable way. In this case, the business was positively impacted due to a higher number of product demonstrations and good sales results.

Even though it's not possible to directly link the platform with the achieved business results, Yammer was the platform used to engage users in the competition.

\section{$5 \quad$ Discussion and Conclusion}

The company mainly relies on the information provided by Tryane Yammer Analytics to assess the success of the network. Even though there is an overall concern to assess the business impact from using such technology, the reality is that the main success criteria is based on the total number of users and the percentage of active users. These indicators are specifically identified as measures of the usage of the platform.

However, there is an understanding that analytics platforms are limited when there is the need to assess a new set of benefits that can't be measured using analytics tools. Log analysis, among other analytic methods, can be used to measure the usage of a platform [12]. However, when business value needs to be assessed, authors seem to resort among other, in a set of qualitative methods as users interviews [12]. This evidence expresses the need to select the approach depending on the intended assessment. These ideas were referred by INT-3 when "asking the users" is presented as a valid and non-quantitative alternative to assess the success of the network. Indeed, a quantitative assessment of ESN business impact seems difficult, mainly when organizational global results are desired. Measuring reduced times to find information or reduced amounts of emails seem to be more attainable indicators [12].

The existence of successful Yammer initiatives that have a trackable (direct or indirect) impact in business results provide an evidence of ESN success. The demonstrations competition in Mexico illustrates how Yammer social features can be useful to accomplish organizational targets.

In summary, the evidence from data collection in this multinational corporation suggests that the assessment of ESN success falls into two dimensions: usage and business value. However, the company resorts heavily on usage information. A clear concern to assess the impact of the ESN on business value appears later. Innovations are only worth it if they are used in work processes, thus, their benefits have to be clearly explained to end-users so they can understand how to take advantage of such tools for their own work [16]. Therefore, companies should start assessing the ESN success from the very first beginning to understand the impact of Yammer in work routines and business results. A clear understanding of these aspects would not only be a clear proof of concept for ESN introduction, as it would also be important for users to understand why ESN is used and ultimately how the organization can benefit from it.

Acknowledgements. This work has been supported by COMPETE: POCI-01-0145FEDER-007043 and FCT - Fundação para a Ciência e Tecnologia within the Project Scope: UID/CEC/00319/2013. 


\section{References}

1. G. Bell, "Enterprise 2.0: bringing social media inside your organization: An interview with Monika Wencek, Senior Customer Success Manager at Yammer," Hum. Resour. Manag. Int. Dig., vol. 20, no. 6, pp. 47-49, 2012.

2. K. Riemer and A. Tavakoli, "The role of groups as local context in large Enterprise Social Networks: a case study of Yammer at Deloitte Australia," Bus. Inf. Syst. Work. Pap. Ser. Univ. Sydney, 2013.

3. K. Ortbach and J. Recker, "Do good things and talk about them: a theory of academics usage of enterprise social networks for impression management tactics," in Proceedings of the 35th International Conference on Information Systems, 2014, pp. 1-13.

4. C. Qi and P. Y. K. Chau, "An empirical study of the effect of enterprise social media usage on organizational learning," Proc. Pacific Asia Conf. Inf. Syst., 2016.

5. B. Wehner, C. Ritter, and S. Leist, "Enterprise social networks: a literature review and research agenda," Comput. Networks, vol. 114, pp. 125-142, 2016.

6. P. M. Leonardi, M. Huysman, and C. Steinfield, "Enterprise social media: definition, history, and prospects for the study of social technologies in organizations," J. Comput. Commun., vol. 19, no. 1, pp. 1-19, 2013.

7. S. Anderson and K. Mohan, "Social networking in knowledge management," IT Prof., vol. 13, no. 4, pp. 24-28, 2011.

8. N. B. Ellison, J. L. Gibbs, and M. S. Weber, "The use of enterprise social network sites for knowledge sharing in distributed organizations: The role of organizational affordances," Am. Behav. Sci., vol. 59, no. 1, pp. 103-123, 2015.

9. J. Dimicco, D. R. Millen, W. Geyer, C. Dugan, B. Brownholtz, and M. Muller, "Motivations for social networking at work," in ACM conference on Computer Supported Cooperative Work, 2008, no. April 2016, pp. 711-720.

10. N. Drakos, J. Mann, and C. Rozwell, "Magic quadrant for social software in the workplace," Gartner, vol. 207256, pp. 2-27, 2010.

11. W. H. DeLone and E. R. McLean, "Information systems success: The quest for the dependent variable," Inf. Syst. Res., vol. 3, no. 1, pp. 60-95, 1992.

12. A. Richter, J. Heidemann, M. Klier, and S. Behrendt, "Success Measurement of Enterprise Social Networks," Wi, no. August, pp. 1-15, 2013.

13. C. Herzog, A. Richter, M. Steinhüser, U. Hoppe, and M. Koch, "Methods and metrics for measuring the success of Enterprise Social Software - what we can learn from practice and vice versa," ECIS 2013 Complet. Res., pp. 1-12, 2013.

14. M. Steinhueser, C. Herzog, and A. Richter, "A process perspective on the evaluation of enterprise social software," in 2nd European Conference on Social Media, 2015, no. July, pp. 429-436.

15. J. Bughin, "Taking the measure of the networked enterprise," McKinsey $Q$., vol. 10, pp. 1-4, 2015.

16. R. T. Frambach and N. Schillewaert, "Organizational innovation adoption: A multilevel framework of determinants and opportunities for future research," J. Bus. Res., vol. 55, no. 2, pp. 163-176, 2002. 